\title{
COMPETITIVIDAD DE LOS HARAS DE SANGRE PURA DE CARRERA EN FUNCIÓN DE LOS FACTORES CLAVE DE ÉXITO
}

\author{
THE COMPETITIVENESS OF THE ARGENTINIAN THOROUGHBRED STUD FARMS \\ THROUGH THE IDENTIFICATION OF CRITICAL FACTORS OF SUCCESS
}

\author{
Paz, S. ${ }^{1 *} ;$ Aulicino, J.M. ${ }^{1}$ y Pereyra, A. ${ }^{1}$ \\ ${ }^{1}$ Facultad de Ciencias Agrarias. Universidad Nacional de Lomas de Zamora. Llavallol. Argentina. \\ *ingspaz@yahoo.com.ar
}

\section{Palabras clave adicionales}

Equipamiento. Programa sanitario. Ubicación.

\section{RESUMEN}

La industria hípica en general y la de Sangre Pura de Carrera (SPC) en particular, es un sector preponderante en la economía agraria argentina. Un grupo reducido de empresas se alternan permanentemente entre los diez primeros lugares de Stud Book de SPC, condición que permite establecer que las mismas poseen factores claves de éxito (FCE), tanto por su gestión empresarial como productiva. Este trabajo, mediante la realización de una encuesta a 20 empresas de SPC pertenecientes al Stud Book, intenta determinar la presencia de FCE. Se estudiaron 52 variables reunidas en siete áreas temáticas de FCE (ubicación geográfica, infraestructura, modelo productivo, recursos tecnológicos, equipamiento aplicado a la producción y programa sanitario). Se detectaron tres grupos productivos claramente regionalizados $y$ un grupo disperso de empresas, asimismo se detectó heterogeneidad con respecto a los éxitos comerciales y deportivos además de diferentes niveles de adopción de innovaciones productivas. El agrupamiento ubicado en el norte de la Provincia de Buenos Aires (Argentina), podría ser considerado como equivalente a un distrito industrial, por la coexistencia de cooperación-competencia. En esta zona se concentra la mayoría de las empresas exitosas. El presente trabajo pretende ser un aporte de nuevos conocimientos relativos al sector hípico del SPC argentino.

\section{SUMMARY}

The horse racing industry in general, and the

\author{
AdDitiONAL KEYWORDS \\ Location. Sanitary program. Facilities.
}

Thoroughbred (SPC), in particular, is a leader sector in the agricultural economy of Argentina. A small group of companies constantly alternates among the top ten places in the Stud Book of SPC, a condition that establishes that they dispose the key factors of success (FCE), both in business and productive managements. This research, by conducting a survey on 20 companies belonging to the Stud Book SPC, tries to determinate the presence of FCE. There were 52 variables collected in seven thematic areas of FCE (geographical location, infrastructure, production model, technological sources, equipment applied to production and sanitary program). This research identified three groups clearly regionalized and a dispersed group of companies. It also detected heterogeneity respect to commercial and sporting success as well as different levels of decision-productive innovations. The cluster located in the north of the Province of Buenos Aires (Argentina), could be considered as the equivalent to an industrial district, because of the coexistence of cooperation-competition. This area concentrates most successful companies. This study intended to be a contribution to knowledge and characterization of the SPC equestrian industry in Argentina.

\section{INTRODUCCIÓN}

Dentro de la estructura del sistema agrario argentino, la cadena de la industria hípica ocupa un lugar de importancia, sustentado en un conjunto de bondades climáticas, 


\section{PAZ, AULICINOY PEREYRA}

edáficas, y un fuerte acervo de cultura hípica, que ha erigido a nuestro país como un referente en la industria hípica internacional (Le Courtois, 2005).

Hay muy pocos estudios sistemáticos relativos a la importancia y dimensión empresarial de las empresas hípicas argentinas que generan unos 180000 puestos de trabajo directos e indirectos.

Esta cadena está formada por tres subsectores productivos: a) la producción de carne equina, siendo Argentina el primer exportador mundial, con 33407 toneladas de producto, equivalente a 210000 animales/ año (Regúnaga et al., 2007); b) el deportivo, generador de fuertes ingresos fiscales por medio del mercado de apuestas y c) la exportación en vivo de animales de alto rendimiento deportivo, con 7106 animales/año (Regúnaga et al., 2007).

A partir de la introducción del caballo Sangre Pura de Carrera (SPC) en Argentina en el siglo XIX, la actividad constituyó un verdadero sistema productivo, basado en una sólida adopción de tecnología y prácticas, consolidando el desarrollo y competitividad del subsector del SPC, que posteriormente se transfirió a las restantes razas equinas deportivas.

Los haras o empresas de SPC pueden definirse como un sistema de producción intensivo, cuyo producto es de alto valor agregado y en el que la competitividad es el resultado final de la eficiencia deportiva y económica de la empresa.

Las ventajas competitivas de las empresas de SPC pueden resumirse en una serie de variables que se constituyen como factores clave de éxito (FCE), que son aquellos elementos del sistema considerados claves o indispensables para el éxito de la empresa (Lasso y Ostertag, 2009) y le permiten sobrevivir y prosperar en un mercado competitivo. Para lograr este objetivo, la empresa debe cumplir dos condiciones: a) suministrar a los consumidores lo que necesitan, lo que desean adquirir, y b) sobrevivir a la competencia. En la actualidad, la empresa debe ingeniárselas para resistir la presión que efectúan sus competidores. Por ello, debe conocer a la perfección el mercado del que participa y las reglas del juego que lo rigen.

Los FCE son las herramientas que permiten alcanzar los objetivos trazados, mejorando el rendimiento competitivo. Existe cierto consenso en que los recursos tecnológicos y las vinculaciones empresariales son cada vez más importantes para determinar el desempeño y competitividad de las unidades económicas (López y Lugones, 1998).

El presente trabajo pretende describir y analizar, por medio de una encuesta, los factores clave de éxito, como determinantes de la competitividad de los haras de Sangre Pura de Carrera en Argentina.

\section{MATERIAL Y MÉTODOS}

Se utilizaron datos primarios obtenidos mediante una encuesta anónima, elaborada en conjunto por las Cátedras de Equinotecnia, Comercialización Agropecuaria y Estadística de la Facultad de Ciencias Agrarias de la Universidad Nacional de Lomas de Zamora. También se consideraron las estadísticas oficiales del ranking del Stud Book Argentino del período 2007-2008.

El trabajo de campo se realizó entre abril de 2008 y abril de 2009, obteniéndose veinte encuestas válidas sobre la población de cincuenta haras que conforman el referido ranking, mediante una selección aleatoria. El trabajo de campo presentó algunas complicaciones originadas en la escasa colaboración prestada por parte de los establecimientos encuestados, los que expresaron cierta reticencia a brindar la información requerida. Con las respuestas obtenidas, se consolidó una base de datos. El cuestionario se conformó por preguntas cerradas, de respuesta única y de respuesta múltiple. Para la valoración se utilizó una escala de Likert de cinco puntos.

Asimismo se generaron las valoraciones para los FCE de un haras ideal, en el cual todas las variables poseen su máxima 


\section{COMPETITIVIDAD DE SPC YFACTORES CLAVE DE ÉXITO}

expresión. La encuesta se estructuró sobre siete áreas temáticas, que reflejaron la adopción o no de FCE en los cuales se sustenta el éxito deportivo y comercial de la misma:

1) Variables de ubicación: localización geográfica de los haras.

2) Variables relativas a los modelos productivos: sistema de producción; análisis de suelos; análisis de agua de bebida; análisis de pasturas; labores de campo.

3) Variables de infraestructura: electricidad por generación propia y de red; equipo de entrenamiento propio; caminador mecánico; lazareto; padrillera; área específica de destete (boxes); área específica de cuida (boxes); área específica de yeguas madres (boxes); área específica de terapia intensiva (boxes); bebedero en boxes; comederos en boxes; iluminación en boxes; ventilación en boxes; climatización en boxes; rociador para insecticida en boxes; boxes herméticos; comunicación en boxes.

4) Variables relativas a la reproducción: área de maternidad específica; área de neonatología específica; balanzas propia específica de neonatos; ecógrafo propio; equipo radiológico propio; fibroscopio propio; banco de calostro; banco de plasma; equipo de oxígeno propio; asistencia de partos; recepción de yeguas a servicio; envío de yeguas a servicio; utilización de estimulación lumínica.

5) Variables de programas sanitarios y diagnóstico: análisis de laboratorio no obligatorio; análisis coproparasitológico; análisis bacteriológico; medición de hormonas en sangre; evaluación de semen en laboratorio; realización de biopsia uterina; análisis espermático a campo; determinación de grupo sanguíneo; realización de autovacunas.

6) Variables de uso de recursos tecnológicos: utilización de ecografía; utilización de radiología; utilización de fibroscopía; utilización de lazareto; acceso a internet.

7) Variables relativas a los recursos humanos: Capacitación del personal; selección del personal.
Para finalizar, se realizó la sumatoria del puntaje obtenido por cada haras de acuerdo al estado de situación individual, calculándose el promedio aritmético para cada agrupamiento, confrontándolo con el haras ideal, en el cual se obtiene el máximo puntaje en cada una de las variables.

La encuesta se procesó estadísticamente mediante el paquete Infostat versión 2010 , realizándose distribuciones de frecuencias para cada variable, agrupadas en las siete temáticas de interés.

\section{RESULTADOSYDISCUSIÓN}

Es notable la polarización de los éxitos deportivos y las ventas de animales en unas pocas empresas, localizadas en el territorio norte de la Provincia de Buenos Aires. Estas se alternan en los primeros puestos del ranking de la clasificación del Stud Book Argentino encargado de las estadísticas sectoriales.

Del análisis de las respuestas obtenidas surgen las siguientes consideraciones, agrupadas por área temática:

\section{VARIABLESDEUBICACIÓN}

De la localización y agrupación por territorio geográfico de las cincuenta principales empresas (haras) de SPC que aparecen en el ranking del Stud Book Argentino, surgen agrupaciones geográficas homologables a conglomerados o distritos industriales. Si bien la definición de conglomerado elaborada por López y Lugones (1998) para identificar modelos productivos empresariales y sectoriales tiene su origen en la industria tradicional, puede ser utilizada para este estudio.

Concurrentemente desde la perspectiva del medio ambiente se fortalece este concepto, el cual establece que, en la concentración territorial, existe un sistema de relaciones en el cual hay conocimientos comunes que resultan de convenciones y lenguajes compartidos, mecanismos de recolección y decodificación de la información. 


\section{PAZ, AULICINOY PEREYRA}

Estas agrupaciones empresariales se basan en condiciones institucionales, sociales, históricas, culturales etc., que proveen la plataforma para el desarrollo del sector empresarial del SPC argentino, observándose comportamientos heterogéneos y distintos ambientes productivos (tabla I y figura 1)

Es notable la concentración de haras que han presentado éxito deportivo y comercial en el agrupamiento ubicado en Buenos Aires norte, con $60 \%$ de los registrados en el Stud Book Argentino y la diferencia con las demás localizaciones.

I) Buenos Aires norte: conformado por partidos del norte de la provincia de Buenos Aires; de los 50 haras localizados siete de ellos se ubican en los 10 primeros lugares del ranking.

II) Pampeano: conformado por 5 haras, dispersos en una amplia región que incluye: el sur de las provincias argentinas de Córdoba y Santa Fe, noreste de la provincia de La Pampa y noroeste de la provincia de Buenos Aires. Ninguno de ellos se encuentra dentro de los diez primeros lugares del Stud Book Argentino.

III) Mar y sierras: comprende el centro y sudeste de la provincia de Buenos Aires. De los cinco haras localizados, sólo uno se encuentra entre los diez primeros lugares del Stud Book Argentino.

Además, diez haras se encuentran dispersos territorialmente, los que, coincidentemente, no aparecen entre los primeros lugares del ranking 2008.

La concentración geográfica de los haras de SPC argentinos, no sólo se justifica tradicionalmente a partir de condiciones agroambientales favorables sino que, además, añade un grado de interacción entre ellos (cooperación-competencia) que puede generar sinergia empresarial. Esto coincide con lo expuesto por Camagni (1991) que expresa que la combinación entre radicación geográfica, calidad de los planteles, recursos técnicos, dotación de recursos humanos, en conjunto con las habilidades de adaptación a innovaciones productivas, conforman finalmente los factores determinantes del éxito o fracaso de cada empresa en particular y de un sector en su conjunto. La relación entre la economía, la regionalización de la producción y el conocimiento se encuentra debidamente probada. A su vez Hamphrey y Schmitz (1996) expresaron que este modo de vinculación productivo alimenta al mismo tiempo la rivalidad y la cooperación entre los productores, generando una amalgama que se expresa en desarrollos sectoriales informales pero tangibles.

Esta relación entre geografía y éxito se hace evidente en el agrupamiento I: Buenos Aires norte, por la concordancia entre localización y ranking. En contraste, los agrupamientos II, III y más aún otras radicaciones (IV), no reflejan esta sinergia.

Es de destacar que la existencia de este medio ambiente de especialización contribuye al desarrollo, introducción, difusión y uso de innovaciones, las que en su conjunto tienen por objeto el desarrollo sectorial. En este sentido Camagni (1991) también expresó que se estimulan las actividades innovativas de las firmas que pertenecen al mismo ámbito y especialidad. En esta perspectiva se enfatizan las relaciones socioculturales por proximidad y competencia

Tabla I. Localización geográfica de los agrupamientos de haras $S P C$, acorde al ranking del Stud Book Argentino (SBA). (Geographical location of Thoroughbred horses haras, acording to the Argentine stud book (SBA)).

\begin{tabular}{lccc}
\hline & CR SBA & CO & FCE \\
\hline Buenos Aires norte (I) & 30 & 14 & 5 \\
Mar y Sierras (II) & 5 & 4 & 3 \\
Pampeano (III) & 5 & 2 & 2 \\
Otras radicaciones (IV) & 10 & 0 & 0
\end{tabular}

$\mathrm{CR} \mathrm{SBA}=$ casos en el ranking $\mathrm{SBA} ; \mathrm{CO}=$ casos obtenidos; $F C E=$ factores clave de éxito. 


\section{COMPETITIVIDAD DE SPC YFACTORES CLAVE DE ÉXITO}

pero, principalmente, aquellas de carácter informal o imitativo.

Se debe tener en cuenta que todo sistema productivo que evoluciona a partir de su carácter innovativo, debe incluir no sólo a las iniciativas privadas, sino también a universidades, institutos técnicos y laboratorios de investigación y desarrollo, que generan información de carácter público y accesible. En este aspecto, Johnson y Lundvall (1994) incorporan el nivel general de educación y destreza, la organización laboral y las relaciones industriales que tienen crucial importancia en el modelo productivo, tanto como los organismos que financian las inversiones.

\section{VARIABLES RELATIVAS ALOS MODELOS PRO- DUCTIVOS}

Un $60 \%$ de los encuestados se dedica exclusivamente a la producción equina, mientras que el resto manifestó desarrollarla en forma mixta con agricultura. Esto deja de manifiesto que la mayoría de los haras, se comportan como empresas puras, lo que las obliga a la eficiencia empresarial, ya que impide las compensaciones con otras actividades agropecuarias comerciales, como por ejemplo dedicar un porcentual del territorio a tareas agrícolas para solventar ineficiencias en la producción de los equinos. Por otra parte, un $20 \%$ de los encuestados realiza actividades de cría

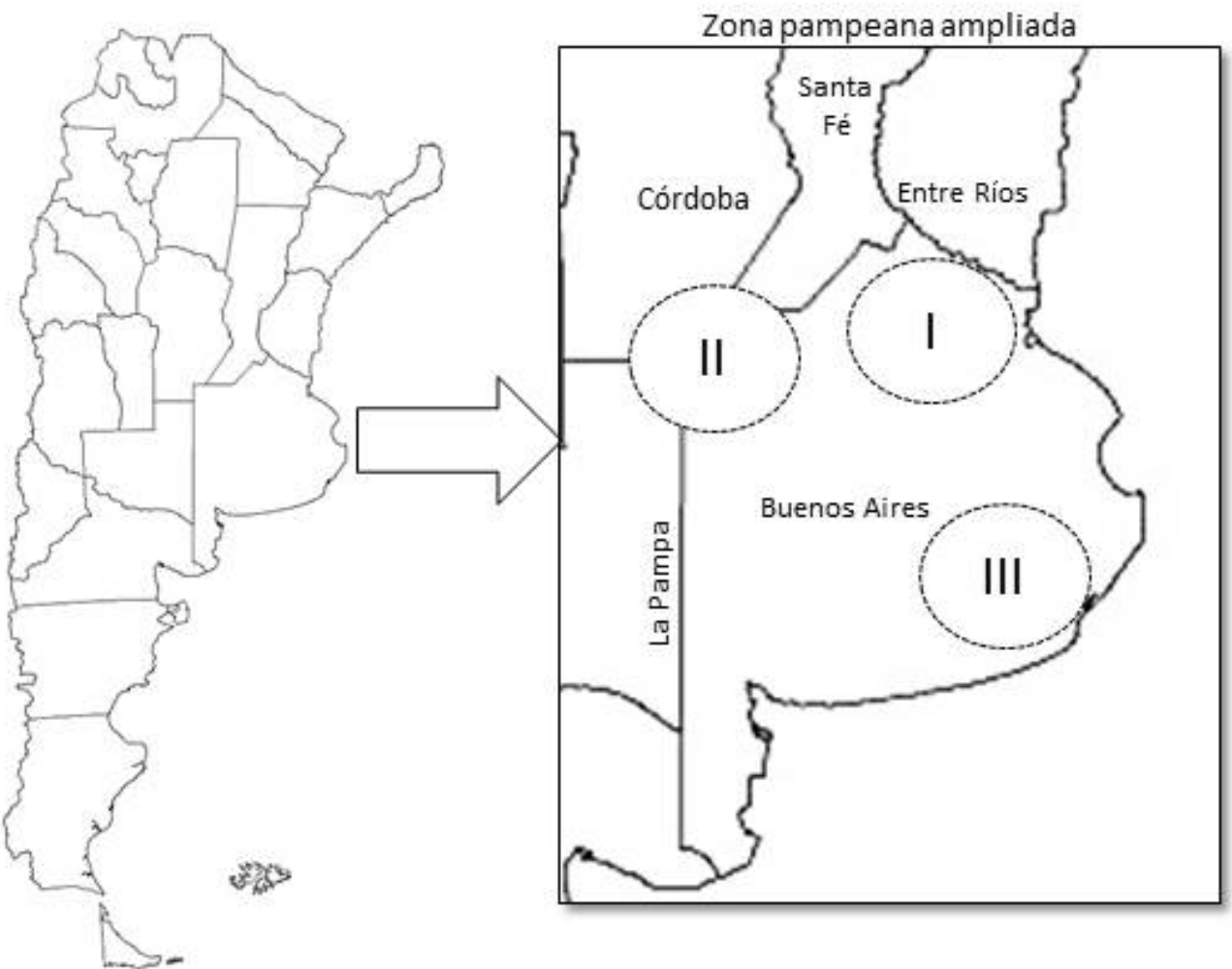

Figura 1. Localizacion geografica de los agrupamiento de haras SPC. (Geographical position of Thoroughbred horses haras agrupations).

Archivos de zootecnia vol. 62, núm. 239, p. 337. 


\section{PAZ, AULICINOY PEREYRA}

equina y agrícola, en campos separados. De ellos, la mitad destina parte de la producción agrícola a la elaboración de los alimentos para sus propios planteles (tabla II).

Se observa, también, que las rutinas analíticas no están incorporadas al sistema de producción como herramientas de eficiencia. Las labores de campo denotan una leve tendencia a la tercerización de las tareas agrícolas en detrimento del equipamiento propio, acorde con el número de empresas dedicadas a la actividad equina con exclusividad y al tiempo muerto de la dotación de maquinarias.

Los porcentajes de utilización de herramientas de análisis de suelo y agua, resultaron del 5 y $15 \%$ respectivamente, mientras que un $55 \%$ no realiza ningún tipo de análisis de pasturas como rutina.

Los resultados de estas variables muestran, además, cierto grado de despreocupación en cuanto al recurso suelo, su conservación, su calidad y previsibilidad de producción de pasturas, lo cual se contradice con el modelo de producción pastoril como base alimenticia (tabla II).

\section{VARIABLESDE INFRAESTRUCTURA}

La presencia de infraestructura como expresión del capital invertido, la tecnología y la formación de recursos humanos incorporados a la empresa, se consideran un FCE, que agrupa diversas variables (confort, materno/neonatología y recursos humanos)

En primera instancia podría expresarse que las instalaciones, el equipamiento y las prácticas aplicadas denotan cierta tendencia a las tradiciones históricas productivas. Sin embargo, las áreas y equipos destinados a los cuidados de los partos así como los neonatos, expresan la preocupación por el cuidado del producto. Al mismo tiempo, es de destacar que, algunas instalaciones tradicionales como son las padrilleras y sobre todo el sector de cuida, en el que se prepara a los productos para la etapa deportiva o la venta, se encuentran ampliamente
Tabla II. Adopción de factores clave de éxito (FCE) relativos a los modelos productivos. (Adoption of key success factors (FCE) related to production models).

\begin{tabular}{lccc}
\hline & \multicolumn{3}{c}{ Positivos Valoración } \\
& $\mathrm{n}$ & $\%$ & $\mathrm{FCE}$ \\
\hline $\begin{array}{l}\text { Sistema de producción } \\
\quad\end{array}$ & & & \\
$\quad \begin{array}{l}\text { Exclusivo caballos } \\
\text { Mixto con agricultura }\end{array}$ & 4 & 60 & 5 \\
$\quad$ Ambos por separado & 4 & 20 & 3 \\
Análisis de suelo & & & \\
$\quad$ Realiza & 1 & 5 & 5 \\
$\quad$ Realiza esporádicamente & 1 & 5 & 2 \\
$\quad$ No realiza & 18 & 90 & 1 \\
Análisis de agua de bebida & & & \\
$\quad$ Realiza & 3 & 15 & 5 \\
$\quad$ Realiza esporádicamente & 2 & 5 & 3 \\
$\quad$ No realiza & 15 & 75 & 1 \\
Análisis de pasturas & & & \\
$\quad$ Realiza & 7 & 35 & 5 \\
$\quad$ Realiza esporádicamente & 2 & 10 & 3 \\
$\quad$ No realiza & 11 & 55 & 1 \\
Labores de campo & & & \\
$\quad \begin{array}{l}\text { Por cuenta propia } \\
\text { Contratadas }\end{array}$ & 9 & 45 & 5 \\
& 11 & 55 & 2 \\
\hline
\end{tabular}

difundidas (90 y $100 \%$ respectivamente) (tabla III).

En el caso de los bebederos dentro de los boxes se encontró que sólo el $20 \%$ adoptó la modalidad de recarga automática. Un alto porcentaje mantienen los sistemas de recarga manual total o parcialmente. Con referencia a los comederos y la luz artificial dentro del box se encontró una mayor proporción de casos positivos, $95 \%$. La regulación térmica dentro de los boxes, crucial para el bienestar de los animales confinados, mostró que un $40 \%$ posee ventiladores de techo, mientras que solo el $5 \%$ presentó sistemas de climatizador central (frío-calor) (tabla III).

Con respecto a los rociadores para insecticidas, se observó una baja adopción, un $10 \%$ en la totalidad de las instalaciones, y un $15 \%$ en la mitad de los boxes.

En cuanto a la comunicación lateral en- 


\section{COMPETITIVIDAD DE SPC YFACTORES CLAVE DE ÉXITO}

tre boxes, un $85 \%$ de la muestra no la posee, mientras que solo un $40 \%$ cuenta con boxes herméticos.

\section{VARIABLES RELATIVAS ALA REPRODUCCIÓN}

Para este grupo de variables resulta importante destacar que el área reproductiva

Tabla III. Adopción de factores clave de éxito (FCE) relativos a la infraestructura. (Adoption of key success factors (FCE) related to infrastructure).

\begin{tabular}{|c|c|c|c|}
\hline & \multicolumn{3}{|c|}{ Positivos Valoración } \\
\hline & $\mathrm{n}$ & $\%$ & FCE \\
\hline Electricidad propia y de red & 4 & 20 & 5 \\
\hline Equipo de entrenamiento & 14 & 70 & 5 \\
\hline Caminador mecánico & 7 & 35 & 5 \\
\hline Lazareto & 2 & 10 & 5 \\
\hline Padrillera & 18 & 90 & 5 \\
\hline \multicolumn{4}{|l|}{ Área específica boxes } \\
\hline destete & 12 & 60 & 5 \\
\hline cuida & 20 & 100 & 5 \\
\hline yeguas madres & 11 & 55 & 5 \\
\hline terapia intensiva & 10 & 50 & 5 \\
\hline \multicolumn{4}{|l|}{ Bebedero en box } \\
\hline Total automático & 4 & 20 & 5 \\
\hline $50 \%$ automático & 10 & 50 & 3 \\
\hline Mayoría manual & 3 & 15 & 2 \\
\hline Todo manual & 3 & 15 & 1 \\
\hline Comedero en box & 19 & 95 & 5 \\
\hline Iluminación artificial & 19 & 95 & 5 \\
\hline \multicolumn{4}{|l|}{ Ventilador en boxes } \\
\hline Tiene & 8 & 40 & 5 \\
\hline No tiene & 12 & 60 & 1 \\
\hline Climatizador central & 1 & 5 & 5 \\
\hline \multicolumn{4}{|l|}{ Rociador de insecticidas } \\
\hline Tiene & 2 & 10 & 5 \\
\hline Tiene $50 \%$ & 3 & 15 & 3 \\
\hline No tiene & 15 & 75 & 1 \\
\hline \multicolumn{4}{|l|}{ Comunicación lateral boxes } \\
\hline Tiene & 2 & 10 & 5 \\
\hline Tiene $50 \%$ & 1 & 5 & 3 \\
\hline Tiene menos del $50 \%$ & 10 & 50 & 2 \\
\hline No tiene & 7 & 35 & 1 \\
\hline \multicolumn{4}{|l|}{ Boxes herméticos } \\
\hline Tiene & 4 & 20 & 5 \\
\hline Tiene $50 \%$ & 4 & 20 & 3 \\
\hline No tiene & 12 & 60 & 1 \\
\hline
\end{tabular}

para el equino SPC mantiene algunas limitaciones en cuanto a la incorporación de innovaciones tecnológicas. Esto se debe a que esta raza prohíbe explícitamente la aplicación de cualquier tipo de técnicas de fertilización asistida, aceptando para la inscripción en sus registros únicamente animales nacidos por servicio natural. Esto limita las actividades reproductivas a controles sanitarios, estimulación lumínica de las yeguas madres y monitoreos por equipos de ultrasonografía. Por lo tanto, los FCE se enfocan a la asistencia de partos y al cuidado del neonato.

En referencia al equipamiento incorporado en el área de maternidad, se observa que un $90 \%$ de los haras encuestados tienen un área específica destinada a este fin, y un $35 \%$ área de neonatología, mientras que un porcentaje menor cuenta con balanza para neonatos (tabla IV). Es de destacar, que un caso exitoso, respondió que aún teniendo la infraestructura, ha vuelto a realizar los partos a campo. Basados en la baja frecuencia de complicaciones, que se debe también a las características anatómicas pélvicas de la yegua y en datos históricos de no problemas, muchos criadores optan por un sistema descontrolado hasta que se presentan indefectiblemente, tarde o temprano, el o los partos problemáticos. Por esto según Losinno y Miragaya (2010): $R e$ sulta dificil de entender que personas que invierten mucho dinero en servicios de alta calidad genética, dejen librado al azar un evento potencialmente tan peligroso (y costoso, si sale mal) para el sistema, sobre todo considerando que los potrillos que demoran más de 90 minutos en nacer luego de la ruptura del corioalantoides raramente sobreviven.

En cuanto a la adopción de equipamiento de diagnóstico por imágenes, un $70 \%$ posee ecógrafo propio, mientras que un $50 \%$ cuenta con equipo de fibroscopía y un $25 \%$ con equipo de rayos $X$.

La conformación del agrupamiento I: Buenos Aires norte, en el cual se encuentra 
Tabla IV. Adopción de factores clave de éxito (FCE) relativos a la maternidad y neonatología. (Adoption of key success factors (FCE) relating to maternity and neonatology).

\begin{tabular}{lccc}
\hline & \multicolumn{3}{c}{ Positivos Valoración } \\
& $\mathrm{n}$ & $\%$ & $\mathrm{FCE}$ \\
\hline Área de maternidad & 18 & 90 & 5 \\
Área neonatología & 7 & 35 & 5 \\
Balanza para neonatos & 7 & 35 & 1 \\
Ecógrafo propio & 15 & 75 & 5 \\
Equipo radiológico propio & 5 & 25 & 5 \\
Fibroscopio propio & 10 & 50 & 5 \\
Banco de calostro & 12 & 60 & 5 \\
Banco de plasma & 12 & 60 & 5 \\
Equipo de oxígeno propio & 11 & 55 & 5 \\
Asistencia de partos & & & \\
$\quad$ Siempre & 16 & 80 & 5 \\
$\quad$ Ocasionalmente & 4 & 20 & 3 \\
Servicio & & & \\
$\quad$ Recepción de yeguas & 14 & 70 & 5 \\
$\quad$ Envío de yeguas & 16 & 80 & 5 \\
Estimulaciónlumínica & 19 & 95 & 5 \\
\hline
\end{tabular}

la mayoría de los haras ubicados en los primeros 10 puestos del ranking, se corresponde con la dotación de las instalaciones junto a las comodidades que aportan bienestar a los animales.

\section{VARIABLES DE PROGRAMAS SANITARIOSY DIAGNÓSTICO}

En cuanto a la evaluación de los programas sanitarios, se consultó acerca de algunos análisis que se consideran no obligatorios pero de importancia para la prevención de problemas y enfermedades. Se observó que, salvo los métodos de laboratorio complementarios como los bacteriológicos, los demás ítems consultados poseen resultados que oscilan entre el 25 y el $65 \%$ (tabla V). Analizando los FCE no sólo como confort y equipamiento tecnológico e incluyendo las metodologías de sanidad preventiva (diagnóstico), se observa que los análisis de laboratorio no obligatorios para todos los agrupamientos no se encuentran en al- tos porcentajes de utilización. Las excepciones parecen ubicarse en aquellas pruebas ligadas a problemas de fertilidad como los análisis bacteriológicos.

Los análisis espermáticos y de determinación de grupo sanguíneo demostraron, en suma, un $35 \%$ de aplicación rutinaria o esporádica, mientras que un $65 \%$ utiliza las biopsias uterinas como elemento de prevención o tratamiento. Tampoco los análisis de laboratorio no obligatorios y de rutina productiva denotan una utilización corriente.

\section{VARIABLES DE UTILIZACIÓN DE RECURSOS TECNOLÓGICOS}

El uso de tecnologías diagnósticas como ecografía, radiología y fibroscopía mostró porcentajes de 100,90 y $85 \%$, que se muestran en la tabla VI. Estas características denotan que la incorporación de tecnologías de diagnóstico se encuentra ampliamente difundida y aceptada en este sistema productivo. A la vez, el agrupamiento I: Buenos Aires norte, marca una diferencia en cuanto a la propiedad de los equipos que

Tabla V. Adopción de factores clave de éxito (FCE) relativos a programas sanitarios y diagnóstico. (Adoption of key success factors (FCE) for sanitary and diagnostic programs).

\begin{tabular}{lccc}
\hline & \multicolumn{3}{c}{ Positivos Valoración } \\
& $\mathrm{n}$ & $\%$ & $\mathrm{FCE}$ \\
\hline Análisis laboratorial & & & \\
$\quad$ no obligatorio & 16 & 80 & 5 \\
$\quad$ coproparasitológico & 5 & 25 & 5 \\
$\quad$ bacteriológico & 19 & 95 & 5 \\
$\quad$ hormonas en sangre & 7 & 35 & 5 \\
$\quad$ evaluación de semen & 7 & 35 & 5 \\
Biopsia uterina & 13 & 65 & 5 \\
Análisis esperma a campo & & & \\
$\quad$ Realiza & 5 & 25 & 5 \\
$\quad$ Esporádicamente & 3 & 15 & 3 \\
$\quad$ No realiza & 12 & 60 & 1 \\
Grupo sanguíneo & 4 & 20 & 5 \\
Autovacunas & 13 & 65 & 5 \\
\hline
\end{tabular}




\section{COMPETITIVIDAD DE SPC YFACTORES CLAVE DE ÉXITO}

Tabla VI. Adopción de factores clave de éxito (FCE) relativos a los recursos tecnológicos. (Adoption of key success factors (FCE) related to technology resources).

\begin{tabular}{lccc}
\hline & \multicolumn{3}{c}{ Positivos Valoración } \\
& $\mathrm{n}$ & $\%$ & FCE \\
\hline Utilización de ecografía & 20 & 100 & 5 \\
Utilización de radiología & 18 & 90 & 5 \\
Utilización de fibroscopía & 17 & 85 & 5 \\
Utilización de lazareto & 2 & 10 & 5 \\
Acceso a internet & 10 & 50 & 5 \\
\hline
\end{tabular}

en los demás casos se encuentra tercerizado. Esta cuestión pasa a ser importante ya que resalta una diferencia entre el uso cotidiano y la disponibilidad de turnos de trabajo del personal contratado. Del mismo modo, aquellos haras que se encuentran dentro del agrupamiento I: Buenos Aires norte, y no poseen el equipamiento propio, tienen mayores posibilidades de tercerización de técnicos o empresas de servicios. En cambio, aquellos que se encuentran más aislados no van a ser debidamente asistidos por profesionales o empresas dedicadas a brindar servicios específicos por la escasez de demanda.

La utilización del lazareto es una instalación de uso poco frecuente. Sin embargo, el acceso a internet como material de consulta demuestra ser una herramienta incorporada al uso de los haras encuestados.

\section{VARIABLES RELATIVAS A LOS RECURSOS HUMANOS}

Un $60 \%$ de los encuestados nunca capacitó a su personal en ninguna de las áreas y un $65 \%$ del total contrata al personal por recomendaciones (tabla VII). Considerando que, tanto las condiciones de equipamiento como las capacidades de adaptación a la incorporación de innovaciones resultan motores del desarrollo empresarial, se ha encontrado un alto grado de dispersión en los datos obtenidos para ambos recursos.
Tabla VII. Adopción de los factores clave de éxito (FCE) relativos a los recursos humanos. (FCE adoption related to human resources).

\begin{tabular}{lccc}
\hline & \multicolumn{3}{c}{ Positivos Valoración } \\
& $\mathrm{n}$ & $\%$ & $\mathrm{FCE}$ \\
\hline Capacitación del personal & & & \\
$\quad$ Realiza siempre & 4 & 20 & 5 \\
Realiza esporádicamente & 3 & 15 & 3 \\
$\quad$ Alguna vez realizó & 1 & 5 & 2 \\
$\quad$ No realiza & 12 & 60 & 1 \\
Selección del personal & & & \\
$\quad$ Por curriculum & 1 & 5 & 5 \\
$\quad$ Por pasantías & 2 & 10 & 4 \\
$\quad$ Por avisos & 4 & 20 & 3 \\
$\quad$ Por recomendación & 13 & 65 & 2 \\
\hline
\end{tabular}

Al respecto Yanovsky (1992) afirmó que Es trascendente para el porvenir social del país establecer si un operario vinculado a un complejo proceso de producción biológico, sujeto a método y ajustado a normas, con un enorme bagaje de conocimiento empírico; representa socioculturalmente un experto igualmente avanzado como lo es el operario urbano que mediatiza su actividad con mediciones y herramientas de precisión.

Queda de manifiesto que existe aún, un importante espacio para el incremento o

Tabla VIII. Puntajes máximos por áreas temáticas de los factores clave de éxito (FCE). (High scores by key success factors (FCE) thematic areas).

\begin{tabular}{ccc}
\hline FCE & Variables & $\begin{array}{c}\text { Puntaje máximo } \\
\text { (haras ideal) }\end{array}$ \\
\hline 1 & 1 & 5 \\
2 & 5 & 25 \\
3 & 17 & 85 \\
4 & 13 & 65 \\
5 & 9 & 45 \\
6 & 5 & 25 \\
7 & 2 & 10 \\
Total & 52 & 260 \\
\hline
\end{tabular}


PAZ, AULICINOY PEREYRA

Tabla IX. Detalle de adopción de factores clave de éxito discriminado por área temática y caso relevado. (Detail of key success factors adoption, discriminated by thematic area and surveyed case).

\begin{tabular}{|c|c|c|c|c|c|c|c|c|c|}
\hline \multirow[b]{2}{*}{ Agrupamiento/Caso } & \multicolumn{7}{|c|}{ Puntaje por área temática } & \multirow[t]{2}{*}{ Total } & \multirow{2}{*}{$\begin{array}{l}\text { Diferencia } \\
\text { haras ideal }\end{array}$} \\
\hline & 1 & 2 & 3 & 4 & 5 & 6 & 7 & & \\
\hline \multicolumn{10}{|l|}{ Buenos Aires norte } \\
\hline 1 & 5 & 24 & 65 & 45 & 23 & 20 & 6 & 188 & -72 \\
\hline 2 & 5 & 24 & 23 & 45 & 23 & 15 & 6 & 141 & -119 \\
\hline 3 & 5 & 22 & 55 & 30 & 25 & 20 & 3 & 160 & -100 \\
\hline 5 & 5 & 21 & 45 & 20 & 10 & 5 & 1 & 107 & -153 \\
\hline 7 & 5 & 19 & 45 & 25 & 15 & 20 & 1 & 130 & -130 \\
\hline 8 & 5 & 20 & 36 & 20 & 5 & 20 & 1 & 107 & -153 \\
\hline 9 & 5 & 20 & 36 & 35 & 30 & 25 & 3 & 154 & -106 \\
\hline 11 & 5 & 23 & 41 & 35 & 30 & 25 & 3 & 162 & -98 \\
\hline 14 & 5 & 20 & 28 & 50 & 10 & 20 & 1 & 134 & -126 \\
\hline 15 & 5 & 23 & 46 & 45 & 23 & 20 & 1 & 163 & -97 \\
\hline 16 & 5 & 25 & 41 & 40 & 25 & 25 & 6 & 167 & -93 \\
\hline 18 & 5 & 23 & 51 & 55 & 25 & 25 & 3 & 187 & -73 \\
\hline 19 & 5 & 21 & 36 & 25 & 15 & 25 & 8 & 135 & -125 \\
\hline 20 & 5 & 24 & 36 & 20 & 25 & 25 & 1 & 136 & -124 \\
\hline promedio & 5,0 & 22,1 & 41,7 & 35,0 & 20,3 & 20,7 & 3,1 & 147,9 & 112,1 \\
\hline mediana & 5,0 & 22,5 & 41,0 & 35,0 & 23,0 & 20,0 & 3,0 & 147,5 & $-112,5$ \\
\hline \multicolumn{10}{|l|}{ Pampeano } \\
\hline 10 & 2 & 21 & 41 & 45 & 35 & 25 & 3 & 172 & -88 \\
\hline 13 & 2 & 22 & 36 & 45 & 30 & 15 & 7 & 157 & -103 \\
\hline promedio & 2,0 & 21,5 & 38,5 & 45,0 & 32,5 & 20,0 & 5,0 & 164,5 & $-95,5$ \\
\hline mediana & 2,0 & 21,5 & 38,5 & 45,0 & 32,5 & 20,0 & 5,0 & 164,5 & $-95,5$ \\
\hline \multicolumn{10}{|l|}{ Mar y sierras } \\
\hline 4 & 3 & 22 & 51 & 40 & 25 & 20 & 8 & 169 & -91 \\
\hline 6 & 3 & 21 & 48 & 55 & 25 & 20 & 1 & 173 & -87 \\
\hline 12 & 3 & 23 & 41 & 45 & 45 & 25 & 1 & 183 & -77 \\
\hline 17 & 3 & 18 & 41 & 25 & 10 & 15 & 6 & 118 & -142 \\
\hline promedio & 3,0 & 21,0 & 45,3 & 41,3 & 26,3 & 20,0 & 4,0 & 160,7 & $-99,3$ \\
\hline mediana & 3,0 & 21,5 & 44,5 & 42,5 & 25,0 & 20,0 & 3,5 & 171,0 & $-89,00$ \\
\hline
\end{tabular}

difusión de los beneficios que supone el uso de equipamientos técnicos mediante la selección y preparación de los recursos humanos destinados a su utilización y aprovechamiento integral. Esto puede interpretarse como un objetivo que aún no ha llegado a su máxima expresión de eficiencia. Yoguel y Boscherini (1996) señalan, confirmando la importancia de la variable de las cualidades de los recursos humanos, que los esfuerzos de capacitación efectuados por las empresas son escasos y tienen fuer- tes diferencias por tamaño de la firmas. Aquellas que realizan los mayores esfuerzos en capacitación son las que utilizan una mayor proporción de técnicas y poseen una mayor formalización de procedimientos, y por ende son más exitosas.

\section{DETERMINACIÓN DEL HARASDESPC IDEAL}

Con la finalidad de jerarquizar los 20 haras observados, se dio un puntaje a cada una de las 52 variables, siendo 5 el máximo y 0 la ausencia, agrupadas por área temática. 


\section{COMPETITIVIDAD DE SPC YFACTORES CLAVE DE ÉXITO}

El haras ideal es aquel que cuenta con la máxima tecnología, infraestructura, aplicación de programas sanitarios y diagnóstico, mejores recursos humanos, etc., es decir, que refleja el máximo de adopción de FCE y sería el ideal a alcanzar a nivel nacional, siendo su puntaje 260 (52x5) (tabla VIII).

En la tabla IX, se observa el ranking de los haras según los tres agrupamientos geográficos presentados en la tabla $\mathbf{I}$.

Se observa, en los tres agrupamientos, diferencias no significativas entre el promedio aritmético y la mediana.

I) Buenos Aires norte: se observa que los dos casos más alejados del puntaje ideal comparten los valores mínimos en cuanto a las variables relativas a reproducción, recursos humanos y en modelo productivo.

II) Pampeano: el caso, que se encuentra más alejado del puntaje de haras ideal, coincide con el agrupamiento I: Buenos Aires norte, en que las variables relativas a reproducción, recursos humanos y modelo productivo, son más bajos que el promedio.

III) Mary sierras: se observa un agrupamiento cuyos valores generales se presen$\tan$ bajos en general y con promedios y medianas por debajo de los obtenidos para las agrupamiento I: Buenos Aires norte y II: pampeano.

\section{CONCLUSIONES}

- La metodología utilizada resultó efec- tiva para detectar y caracterizar los factores clave de éxito (FCE) de los haras de Sangre Pura de Carrera (SPC) argentinos, siendo sensible a las diferencias entre empresas y agrupamientos.

- Se pudieron detectar tres agrupaciones de empresas que responden a determinadas localizaciones y un grupo de haras de SPC disperso.

- Solamente el agrupamiento Buenos Aires Norte es asimilable a un distrito industrial, aunque restringido a un pequeño grupo de haras que concentran los éxitos deportivos y comerciales, acercándose al Haras ideal.

- Podría existir una relación directa entre cantidad de FCE adoptados y los éxitos deportivos-comerciales alcanzados.

- El equipamiento y dotación de dispositivos tecnológicos se relacionan de modo directo con los FCE, la capacitación del personal tanto como el modo de selección de recursos humanos debe mejorarse para aportar eficiencia al sistema productivo del SPC en Argentina.

\section{AGRADECIMIENTOS}

A las alumnas de la Facultad de Ciencias Agrarias de la Universidad Nacional de Lomas de Zamora, Argentina, que han colaborado desinteresadamente en el desarrollo del presente trabajo: Señoritas Mariana Flores y Sabrina Radics.

\section{BIBLIOGRAFÍA}

Camagni, R. 1991. Local milieu, university and innovation networks: Towards and new dynamic theory of economic space. Belhaven press. Londres.

Hamphrey, J. e Schmitz, H. 1996. Globalização e inovação localizada: Experiências de sistemas locais no âmbito do mercosul e proposições de políticas de C\&T. Brasil. Nota Técnica 15/98. Rio de Janeiro, março de 1998. Instituto de Economia da Universidade Federal do Rio de Janeiro-IE/ UFRJ. http://www.ie.ufrj.br (16/11/2011).

Johnson, B. y Lundvall, A. 1994 Sistemas nacionales de innovación y aprendizaje institucional, comercio exterior. Comercio Exterior, 44: 695704.

Lasso, L.P. y Ostertag, C.F. 2009. Análisis de factores claves de éxito de agroempresas rurales en la zona andina enfocadas hacia la exportación. Proyecto de Desarrollo de Agroempresas Rurales (CIAT). Buenos Aires. Argentina.

López, A. y Lugones, G. 1998. Los sistemas locales en el escenario de la globalización.

Archivos de zootecnia vol. 62, núm. 239, p. 343. 


\section{PAZ, AULICINOY PEREYRA}

Instituto de Economía da Universidade Federal de Río de Janeiro. Brasil. Nota Técnica 15/98.

Le Courtois, B. 2005. Nuestros caballos, sociedad rural argentina. Universidad Católica Argentina. Buenos Aires. Argentina.

Losinno, L. y Miragaya, M.H. 2010. Parto controlado o descontrolado? Cuándo, por qué y cómo intervenir? Manejo intra y posparto inmediato. Tercer Curso Internacional sobre Medicina Reproductiva, Transferencia Embrionaria y Neonatología Equinas. Universidad de Córdoba. España. Anuario de la Asociación Criadores de Caballos Criollos 2010. Editorial Publicidad Norte. Buenos Aires. Argentina.

Regúnaga, M.; Cetrángolo, H. y Mozeris, G. 2007.
El Impacto de las cadenas agroindustriales pecuarias en la Argentina, evolución y potencial. Facultad de Agronomía. Universidad de San Andrés y Fundación Agronegocios y Alimentos. Buenos Aires. Argentina. 84 pp.

Yanovsky, J. 1992. Reflexiones sobre biotecnología, sociedad y política. Biotecnología, cultura y poder político. Poder político. Cuaderno del CEAgro № 6, 2005. ISNN 1514-8467. Buenos Aires. Argentina.

Yoguel, G. y Boscherini, F. 1996. La capacidad innovativa y el fortalecimiento de la competitividad de las firmas: El caso de las pymes exportadoras argentinas. CEPAL. Documento de trabajo $n^{\circ} 71$. Oficina Buenos Aires.

Archivos de zootecnia vol. 62, núm. 239, p. 344. 